\title{
An Investigation into the Effect of Cracking on the Response of Drilled and Postgrouted Concrete Pipe Pile under Lateral Loading
}

\author{
Zhijun Yang $\left(\mathbb{D},{ }^{1}\right.$ Qing Fang, ${ }^{2}$ Bu Lv, ${ }^{1}$ Can Mei, ${ }^{3}$ and Xudong Fu $\mathbb{D I}^{1}$ \\ ${ }^{1}$ School of Civil Engineering, Wuhan University, Wuhan 430072, China \\ ${ }^{2}$ PowerChina Hubei Electric Engineering Co., Ltd., Wuhan 430040, China \\ ${ }^{3}$ China Railway 11 Bureau Group Co., Ltd., Wuhan 430061, China \\ Correspondence should be addressed to Xudong Fu; xdfu@whu.edu.cn
}

Received 30 June 2019; Accepted 5 December 2019; Published 23 January 2020

Academic Editor: Paolo Andrea Carraro

Copyright ( 92020 Zhijun Yang et al. This is an open access article distributed under the Creative Commons Attribution License, which permits unrestricted use, distribution, and reproduction in any medium, provided the original work is properly cited.

\begin{abstract}
The cracks are likely to initiate on a lateral loaded pile and would cause greater deflection at the pile head. However, there is a lack of thorough investigation into the effect of cracking on the response of the lateral loaded pile. In this article, a full-scale field test was carried out to investigate the behavior of Drilled and Postgrouted Concrete Pipe Pile under lateral loads. A novel analysis method for the lateral loaded pile, which can take the cracking effects into consideration, was proposed, and the validity was verified by the test results. With the proposed method, the cracking effects on flexural rigidity, displacement, rotation, and bending moment of the pile were studied. In brief, cracking effect would dramatically reduce the flexural rigidity of the pile, remarkable increase the displacement and rotation of the pile top, and slightly decrease bending moment of the pile. Unambiguously, the results show that the proposed method can excellently predict the response of laterally loaded piles under cracking effects.
\end{abstract}

\section{Introduction}

The prestressed high-strength concrete (PHC) pipe piles have been widely used in different kinds of practical projects due to the high bearing capacity, convenience of construction, and cost saving [1,2]. However, it is difficult, sometimes even impossible, to drive the pile into the soil. In order to solve the problems of pile driving, a novel pile foundation called the Drilled and Postgrouting Concrete Pipe Pile has been developed, which accomplishes the pile sinking by three steps: (1) drilling a hole with the rotary drilling rig; (2) putting the PHC pipe pile into the middle of the hole; and (3) bonding the pipe pile with soil by grouting cement paste into the gap.

The pile foundation is usually subject to lateral loads transferred from the structure, such as power transmission towers, bridges, high buildings, and offshore wind turbines. The behavior of laterally loaded piles has been studied by many investigators, and several analytical methods have been developed, including the elastic subgrade reaction approach $[3,4]$, the elastic continuum method $[5,6]$, the $p-y$ curve method [7-9], and the strain wedge model [10]. The major difference among these methods is in the assumptions of pile-soil interaction. The lateral response of the pile, in all of these methods, is predicted by solving the differential equation of pile deformation, and the pile was usually treated as an elastic beam [11-14]. However, as for the Drilled and Postgrouted Concrete Pipe Pile, cracks are prone to initiate in both grout layer and PHC pipe pile [15]. In this case, the elastic beam assumption may lead to deviations.

The effect of cracks on the behavior of the lateral loaded pile has been investigated by many researchers, and several analysis methods have been proposed [16-18]. According to the results of field tests and finite element analysis, Comodromos et al. [16] pointed out that the behavior of the lateral loaded pile, especially the lateral displacement, would be significantly affected by the reduction of flexural rigidity caused by the cracking effects. Based on the $p-y$ curve method, Reese [17] proposed an approach to 
consider the cracking effects. In this approach, the pile flexural rigidity is treated as a function of bending moment and updated during calculation. However, if the pile flexural rigidity decreases sharply, the finite difference method adopted in this approach would cause unreasonable results. To solve this problem, Reese [17] employs an approximate function to replace the actual relationship of flexural rigidity and bending moment, and the accuracy is reduced. Xu et al. [18] improved Reese's approach by adopting the modified strain wedge model to calculate the subgrade reaction modulus and the finite element method to solve the pile deflection. However, the modified strain wedge model used in Xu's approach is much more complex than the $p-y$ curve method, which causes Xu's approach more computationally expensive. Moreover, the existing research studies mainly focus on the cracking effects of the cast-in-place pile. The Drilled and Postgrouted Concrete Pipe Pile is a novel foundation type and consists of the PHC pipe pile as the core and the grout layer which is formed by the solidification of grout cement paste. The initiation and development of cracks in the Drilled and Postgrouted Concrete Pipe Pile are more complex than in the cast-in-place pile due to the prestress in the PHC pipe pile and the material diversity. Therefore, more detailed investigations into the effects that cracking brings to the lateral response of the Drilled and Postgrouted Concrete Pipe Pile are meaningful and necessary.

In this article, a full-scale lateral load test was performed to investigate the behavior of the Drilled and Postgrouted Concrete Pipe Pile. The relationship between flexural rigidity and bending moment was studied with the numerical method, and a novel analysis method that combined onedimension beam finite element with $p$ - $y$ curve was proposed. The validity of the proposed method was verified by the test results. Moreover, the proposed method was compared with the well-known $p$ - $y$ method, and the cracking effects on the lateral response of the Drilled and Postgrouted Concrete Pipe Pile are further discussed.

\section{Lateral Static Load Test of the Drilled and Postgrouted Concrete Pipe Pile}

2.1. Drilled and Postgrouted Concrete Pipe Pile. As shown in Figure 1(a), the construction processes of the Drilled and Postgrouted Concrete Pipe Pile can be divided into mainly three steps. Firstly, drilling a hole with the rotary drilling rig. The depth of the hole is equal to the embedded length of the pile, and the diameter of the hole is slightly greater than the diameter of the PHC pipe pile. Secondly, putting the PHC pipe pile into the middle of the hole. Finally, grouting the cement paste into the gap between the PHC pipe pile and the hole with the grout device, which is previously installed at the pile tip. After the cement paste is solidified, the grout layer is formed, and the PHC pipe pile is bonded with the soil.

The Drilled and Postgrouted Concrete Pipe Pile is a novel type of pile foundation which combined the $\mathrm{PHC}$ pipe pile with the postgrout technology. Its characteristics can be summarized as follows. Firstly, the problems in
PHC pipe pile sinking, such as high requirements for the pile driver, damage to the pile body, and difficulties in controlling the verticality of the pile, can be solved by drilling a hole with the rotary drilling rig. Secondly, the failures caused by defects, such as mud inclusion in the cast-in-place pile, can be avoided by putting the PHC pipe pile, which has high member strength, into the middle of the hole. In addition, there are also advantages such as construction time saving, higher degree of mechanization, and less impact on the environment, compared with the cast-in-place pile.

2.2. Lateral Static Load Test. The outline situation of lateral load test is presented in Figure 2. The pile length below and above the ground surface is $13.5 \mathrm{~m}$ and $0.5 \mathrm{~m}$, respectively. The outer and inner diameter of the PHC pipe pile are $0.80 \mathrm{~m}$ and $0.54 \mathrm{~m}$, respectively. In the PHC pipe pile, 15 steel bars, with diameter of $12.6 \mathrm{~mm}$ and yield strength of $1420 \mathrm{MPa}$, are arrayed in a circle of $0.69 \mathrm{~m}$ in diameter. The concrete used in the PHC pipe pile is of grade C80 and with an effective prestress of $6.0 \mathrm{MPa}$.

The grout layer is formed by the solidification of grout cement paste, and its outer and inner diameter is $1.00 \mathrm{~m}$ and $0.80 \mathrm{~m}$, respectively. The proportion of the cement paste is listed as follows: water:cement:water-reducing agent: expanding agent $=32.5 \%: 59.5 \%: 7.1 \%: 0.6 \%$. And cuboid specimens with $40 \mathrm{~mm}, 40 \mathrm{~mm}$, and $160 \mathrm{~mm}$ in length, width, and high, respectively, were obtained for compression and flexural tests. The test results show that the compression and flexural strength of the cement paste cured for 28 days are $47.0 \mathrm{MPa}$ and $11.1 \mathrm{MPa}$, respectively.

Two auger borings were advanced in the vicinity of the pile after lateral load test, and the soil samples were collected for detailed site investigation and accurate determination of the soil parameter. To diminish the impact of sampling disturbance on the soil properties and the analysis results, the soil samples used in the soil tests were obtained with the open thin-wall sampler whose inner wall was lubricated [19]. The soil investigation shows that the cement layer, soft clay layer, and mucky soil layer are existing at the depth of $0.0-0.9 \mathrm{~m}, 0.9-4.0 \mathrm{~m}$, and 4.0-13.5 m, respectively. Before lateral load test, the cement layer within $0.5 \mathrm{~m}$ from the edge of the pile was dug away, and the soft clay was backfilled in order to diminish the influence of the cement layer. The parameters of soft clay and mucky soil are listed in Table 1. The comparison between the calculated results and the field test results, as described in the next section, shows that the influence of sampling disturbance on the properties of soil and analysis results is negligible.

The displacement at the ground surface was determined by the average value of three dial indicators installed near the ground surface. The displacement of the pile top was also measured with another dial indicator installed at the pile top, which is $0.5 \mathrm{~m}$ higher than the ground surface. And the rotation of the pile top was determined by the difference between the displacement at the ground surface and the pile top. 


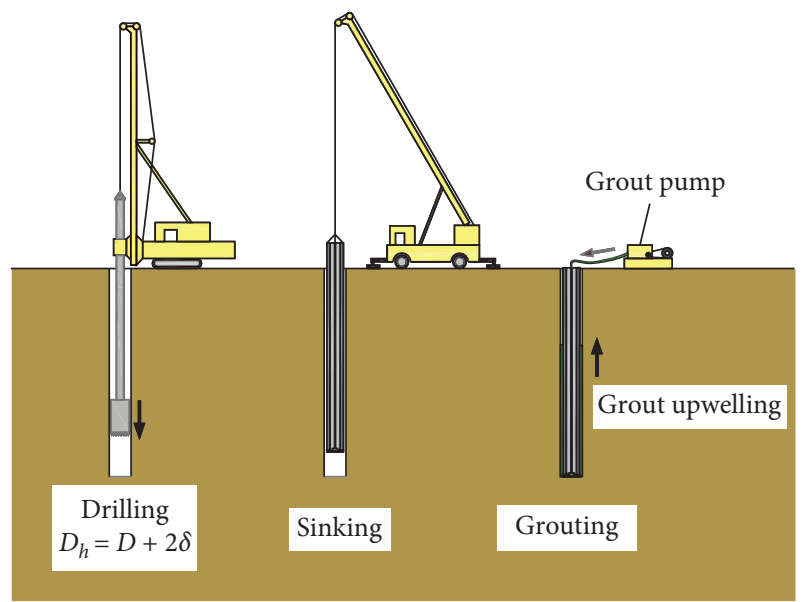

(a)

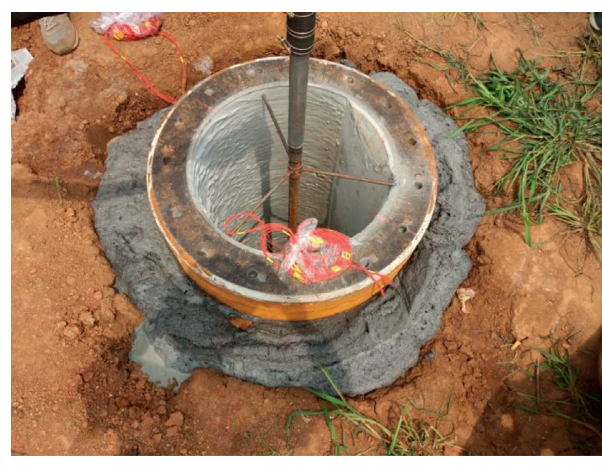

(b)

Figure 1: Drilled and Postgrouted Concrete Pipe Pile. (a) The construction processes. (b) Photo of the Drilled and Postgrouted Concrete Pipe Pile.

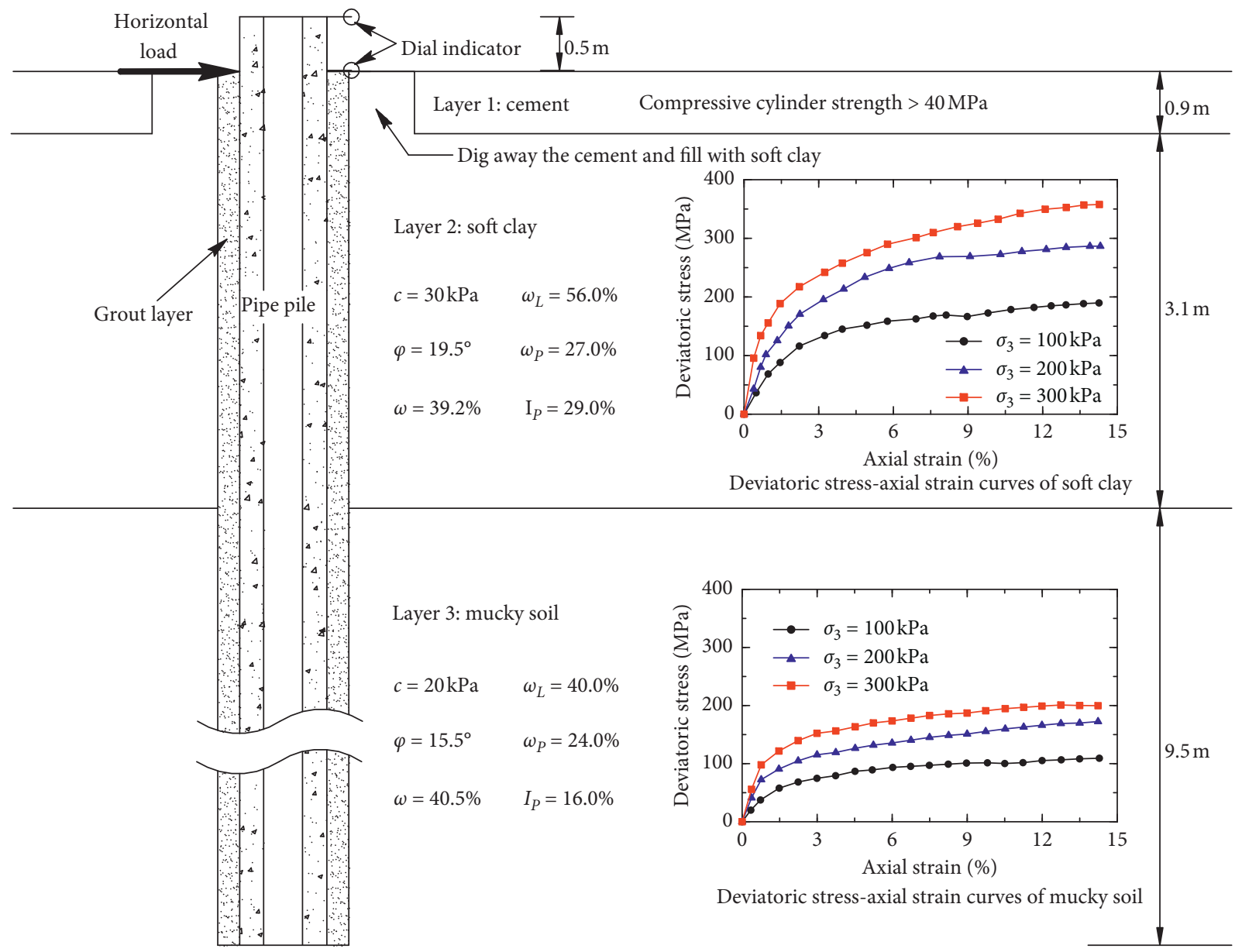

Figure 2: The outline situation of lateral static load test of the Drilled and Postgrouted Concrete Pipe Pile.

The lateral load was applied up to $420 \mathrm{kN}$ by increments of $30 \mathrm{kN}$ at the position near the ground surface. Each load increment was hold on for two hours before recording the displacement and applying the next increment.
2.3. Analysis of Test Results. Firstly, ignoring the cracking effects on the pile and treating the pile as an elastic beam, then the behavior of the laterally loaded pile can be governed by the following fourth-order ordinary differential equation: 
TABle 1: Parameters of soft clay and mucky soil.

\begin{tabular}{lcc}
\hline Soil type & Soft clay & Mucky soil \\
\hline Depth range $(\mathrm{m})$ & $0.9-4.0$ & $4.0-13.5$ \\
Density $\left(\mathrm{g} / \mathrm{cm}^{3}\right)$ & 1.84 & 1.88 \\
Undrained shear strength $c(\mathrm{kPa})$ & 30 & 20 \\
Friction angle $\left(^{\circ}\right)$ & 19.5 & 15.5 \\
Water content $(\%)$ & 39.2 & 40.5 \\
Plasticity index IP (\%) & 29 & 16 \\
Relative water content IL & 0.42 & 1.06 \\
\hline
\end{tabular}

$$
E I \frac{\mathrm{d}^{4} y}{\mathrm{~d} z^{4}}+p(y)=0
$$

where $E I$ is the flexural rigidity of the pile, $y$ is the lateral displacement at depth of $z$, and $p(y)$ is the soil resistance which can be determined by the $p-y$ curves.

The flexural rigidity of the Drilled and Postgrouted Concrete Pipe Pile, which is contributed by the grout layer and the PHC pipe pile, can be calculated as follows:

$$
E I=\frac{E_{g} \pi\left(D^{4}-D_{p}^{4}\right)+E_{c} \pi\left(D_{p}^{4}-D_{i}^{4}\right)}{64}+\left(E_{s}-E_{c}\right) \sum_{i=1}^{n} A_{s i} y_{i}^{2},
$$

where $E_{g}$ and $E_{c}$ are the elasticity modulus of concrete of the grout layer and the PHC pipe pile, respectively; $E_{s}$ is the elasticity modulus of the steel bar; $D$ is the outer diameter of the grout layer; $D_{p}$ and $D_{i}$ are the outer and inner diameter of the PHC pipe pile, respectively; $n$ is the number of steel bar; $A_{s i}$ is the section area of the steel bar $I$; and $y_{i}$ is the distance from the steel bar $i$ to the neutral axis.

As for soft clay and mucky soil, the most widely employed $p-y$ curves are the one that proposed by Matlock [7], which can be expressed by following formulas:

$$
\frac{p}{p_{u}}=0.5\left(\frac{y}{y_{c}}\right)^{1 / 3}
$$

in which $y_{c}=0.25 \varepsilon_{50} D$ and $p_{u}=\min \left(p_{u 1}, p_{u 2}\right) ; D$ is the diameter of the pile, and $\varepsilon_{50}$ is the strain which occurs at onehalf of the maximum stress on a laboratory stress-strain curves; $p_{u 1}$ and $p_{u 2}$ are the ultimate soil resistance corresponding to the wedge and the flow-round failure mode, respectively. Due to the existing of the cement layer at the depth of $0.0-0.9 \mathrm{~m}$, it is impossible for wedge failure to occur. Hence, the ultimate soil resistance is determined by the flowround failure mode, and the value of $9 c D$ is proposed by Matlock [7], where $c$ is the undrained shear strength.

$\varepsilon_{50}$ and the undrained shear strength $c$ can be obtained from the stress-axis strain curves in Figure 2, which are 0.0021 and $30 \mathrm{kPa}$, respectively, for the soft clay and 0.0015 and $20 \mathrm{kPa}$, respectively, for the mucky soil.

The lateral displacement at the ground surface and rotation of the pile top at different loads were calculated by equation (1) and the $p-y$ curves proposed by Matlock [7]. The load-displacement curves and load-rotation curves are plotted in Figure 3, as well as the measured curves.

As shown in Figure 3(a), the measured displacement at the ground surface increases nonlinearly as the lateral load increases. When the load is less than $150 \mathrm{kN}$, the displacement calculated by the $p-y$ method is close to the measured value. However, when the lateral load exceeds $150 \mathrm{kN}$, the displacement calculated by the $p-y$ method is remarkably smaller than the measured value, and the difference increases as the load increases. When the load is $420 \mathrm{kN}$, the measured displacement is $56.8 \mathrm{~mm}$, which is $52.7 \%$ greater than the calculated displacement.

As depicted in Figure 3(b), the measured rotation of the pile top grows nonlinearly as the lateral load increases, and the growth rate of rotation increases obviously when the load exceeds $270 \mathrm{kN}$. The calculated rotation of the pile top is less than the measured value dramatically, especially when the load exceeded $270 \mathrm{kN}$.

The Drilled and Postgrouted Concrete Pipe Pile is composed of the grout layer and the PHC pipe pile, which consist mainly of concrete. Its tensile strength is much lower than the compressive strength. Hence, cracks are prone to initiate in both grout layer and PHC pipe pile. Especially in the grout layer, which is formed by the solidification of grout cement paste and has no prestress, the crack is likely to initiate even when the bending moment is small. The initiation and development of cracks in the grout layer and the PHC pipe pile would reduce the flexural rigidity of the Drilled and Postgrouted Concrete Pipe Pile. However, the cracking effects are ignored in the calculation above, and it maybe the reason why the calculation values of displacement and rotation are lower than the corresponding measured values.

\section{Effect of Cracks on Flexural Rigidity and Bearing Behavior of the Pile}

3.1. Effect of Cracks on Flexural Rigidity of the Pile. Based on the stress-strain relationship of concrete and the steel bar, as well as plane section assumption, Reese [17] proposed an approach to estimating the flexural rigidity of the pile after cracks initiated. Enlightened by that, the effects of cracking on flexural rigidity of the Drilled and Postgrouted Concrete Pipe Pile are analyzed in this section.

As shown in Figure 4, the bending deformation could occur in the pile, and the cracks would initiate at the tensile side when the pile is under lateral load and moment. Taking a pile microsegment with length of $\mathrm{d} z$ into consideration, the coordinate system is established and shown in Figure 4. Assuming that the cracking depth in the grout layer and pipe pile is $t_{1}$ and $t_{2}$, respectively, and the distance from the neutral axis to the circular axis is $h$, then the strain caused by the bending deformation can be determined as follows:

$$
\varepsilon_{b}=\frac{1}{\rho}(y-h),
$$

where $\varepsilon_{b}$ is the strain caused by bending and $\rho$ is the radius of curvature of the pile microsegment.

Taking the effect of prestress, which is existing in the concrete and the steel bar of the PHC pipe pile, into consideration, the total strain can be calculated as follows: 


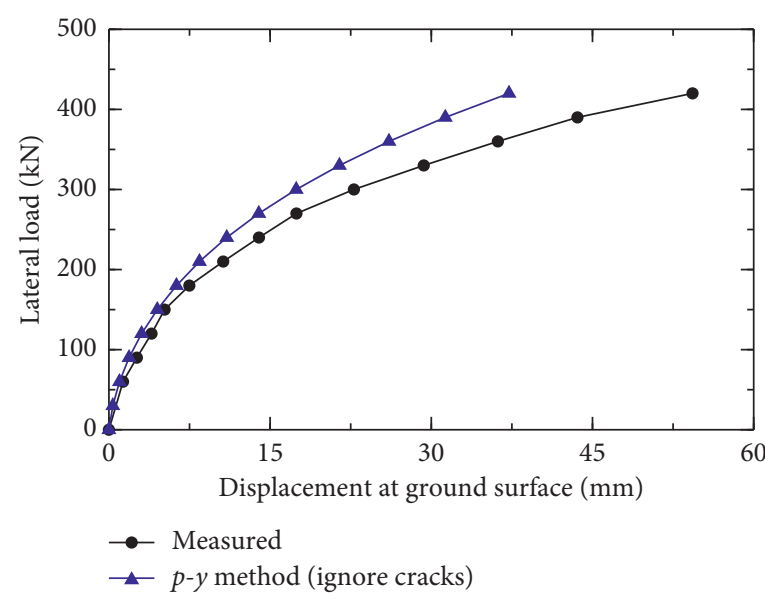

(a)

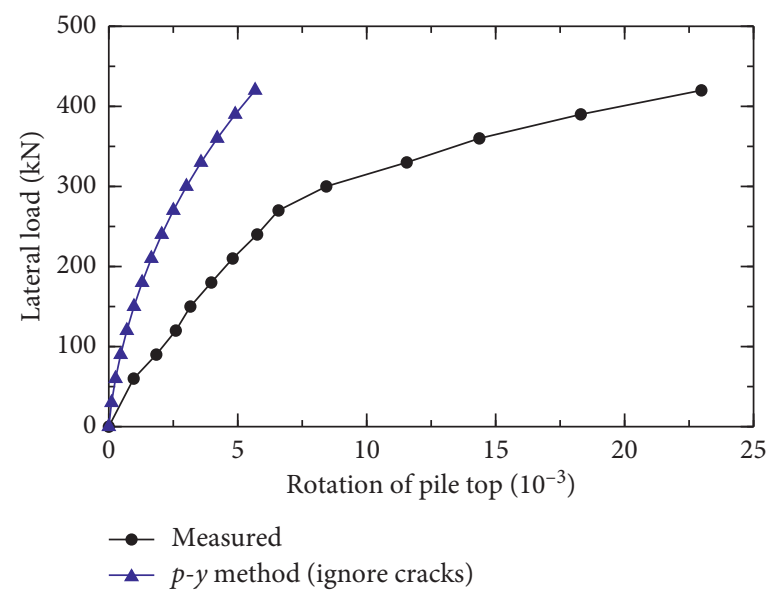

(b)

FIGURE 3: Analysis of test results: (a) load-displacement curves; (b) load-rotation curves.

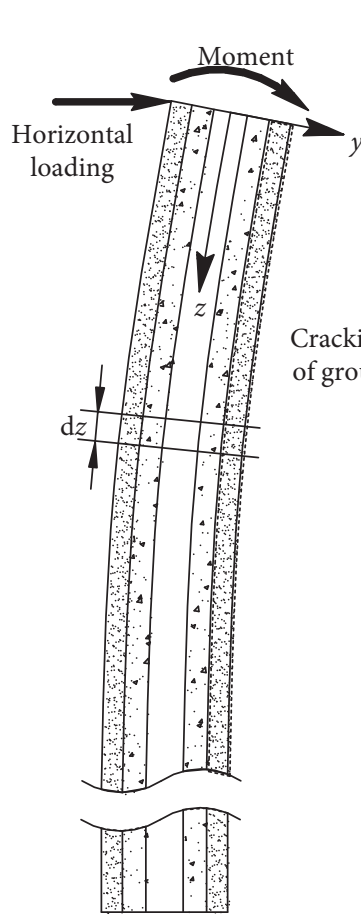

(a)
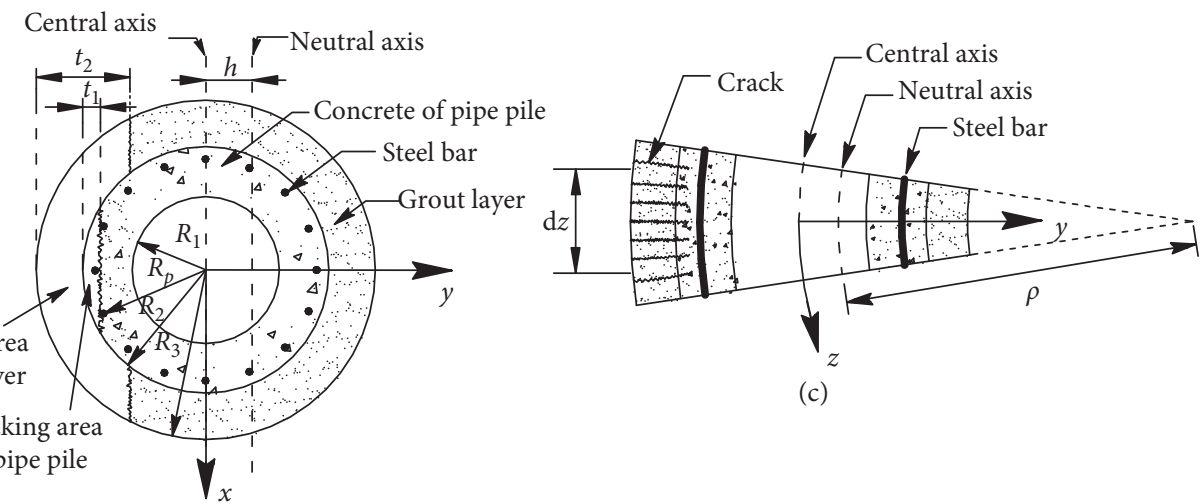

(c)

(b)

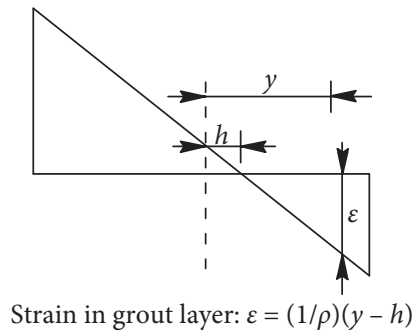

(d)

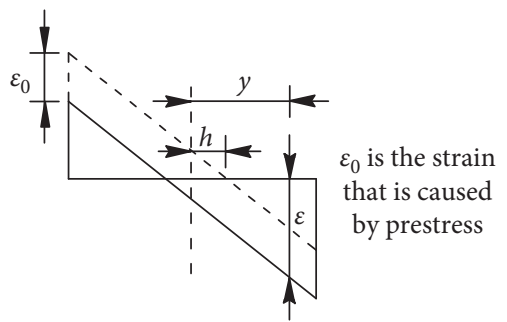

Strain in concrete of pipe pile: $\varepsilon=(1 / \rho)(y-h)+\varepsilon_{0}$

(e)

Figure 4: Cracking effect analysis: (a) force and deformation diagram of the pile; (b) cracks in the pile section; (c) deformation of the pile microsegment; (d) strain distribution in the grout layer; (e) strain distribution in concrete of the pipe pile.

$$
\varepsilon= \begin{cases}\varphi(y-h), & \text { for grout layer } \\ \varphi(y-h)+\varepsilon\left(\sigma_{0}\right), & \text { for pipe pile, } \\ \varphi(y-h)-\frac{\sigma_{0} A_{c}}{n A_{s} E_{s}}, & \text { for steel bar, }\end{cases}
$$

where $\sigma_{0}$ is the effective prestress in the concrete of the pipe pile; $\varepsilon\left(\sigma_{0}\right)$ is the strain of concrete of the pipe pile caused by prestress; $A_{c}$ and $A_{s}$ are the section area of the concrete and the single steel bar of the PHC pipe pile, respectively; and $n$ is the number of steel bar.

The normal stress of the pile section can be calculated with the stress-strain curves of materials. As for the concrete of the PHC pipe pile and the grout layer, when it is in compression status, the stress-strain curves recommended by the China Technical Code for design of concrete structures [20] are employed, which divided the stress-strain relationship into ascend and descend. And when it is in the 
tension status, an elastic model is employed before crack initiation. The stress-strain relationship of concrete of the grout layer and the PHC pipe pile was expressed as equation (6). Ideal elastoplastic model with a yield strength of $1420 \mathrm{MPa}$ is employed for the steel bars.

$$
\sigma= \begin{cases}\frac{f_{t}}{E_{t}} & \varepsilon_{t u} \leq \varepsilon \leq 0, \\ f_{c}\left[2 \frac{\varepsilon}{\varepsilon_{0}}-\left(\frac{\varepsilon}{\varepsilon_{0}}\right)^{m}\right], & 0 \leq \varepsilon \leq \varepsilon_{0}, \\ f_{c}\left[1-0.15 \frac{\varepsilon-\varepsilon_{0}}{\varepsilon_{c u}-\varepsilon_{0}}\right], & \varepsilon_{0}<\varepsilon \leq \varepsilon_{c u},\end{cases}
$$

where $f_{c}$ is the compressive cylinder strength and $m, \varepsilon_{0}$, and $\varepsilon_{c u}$ are the test parameters, which can be determined according to the China Technical Code for design of concrete structures [20].

According to the force equilibrium condition of cross section in $z$ direction, the formula can be written as

$$
\int_{S_{g}} \sigma_{g}(\varepsilon) \mathrm{d} S+\int_{S_{p}} \sigma_{p}(\varepsilon) \mathrm{d} S+\sum_{i=1}^{n} \sigma_{s}(\varepsilon) A_{s i}=0
$$

where $S_{g}$ and $S_{p}$ are the area domain of the grout layer and the concrete of PHC pipe pile in the cross section, respectively. $\sigma_{g}(\varepsilon), \sigma_{p}(\varepsilon)$, and $\sigma_{s}(\varepsilon)$ are stress of the grout layer, concrete of the PHC pipe pile and the steel bar, respectively.

Substituting the expression of the stress-strain relationship into equation (7), the distance from the neutral axis to the circular axis $h$ can be calculated with iteration procedures.

If $h$ was determined, the bending moment, corresponding to the given curvature, can be calculated by

$$
\begin{aligned}
M= & \int_{S_{g}} \sigma_{g}(\varepsilon)(y-h) \mathrm{d} S+\int_{S_{p}} \sigma_{p}(\varepsilon)(y-h) \mathrm{d} S \\
& +\sum_{i=1}^{N_{s}} \sigma_{s}(\varepsilon) A_{s i}\left(y_{i}-h\right),
\end{aligned}
$$

where $y$ and $y_{i}$ are the distance from the central axis to the integral point and steel bar $i$, respectively.

Providing the bending moment-curvature relationship was determined, the flexural rigidity of the pile can be expressed as a function of bending moment as follows:

$$
E I=\frac{M(z)}{\varphi(z)} .
$$

A computer code has been written based on the above procedures, and the curvature-bending moment curves and moment-EI curves are calculated and plotted in Figure 5. The parameters employed are listed in Table 2.

Figure 5(a) shows the relationship between curvature and bending moment. The relationship curve can be divided into four phases. Firstly, phase $\mathrm{OAA}_{1}$ : before point A, no crack initiates in the grout layer or the PHC pipe pile, and the curvature grows linearly with the increasing of bending moment; when the bending moment has increased to $272.5 \mathrm{kN} \cdot \mathrm{m}$, however, the cracks initiate in the grout layer and the curvature grows from point $A$ to $A_{1}$, without bending moment increasing. Secondly, phase $\mathrm{A}_{1} \mathrm{BB}_{1}$ : before point $\mathrm{B}$, the cracks continually develop in the grout layer, while no crack initiates in the PHC pipe pile, and the curvature grows approximately linearly with the increasing of bending moment; when the bending moment has increased to $539.6 \mathrm{kN} \cdot \mathrm{m}$, however, the cracks initiate in the PHC pipe pile and the curvature grows from point $B$ to $B_{1}$, without bending moment increasing. Thirdly, phase $\mathrm{B}_{1} \mathrm{C}$ : the cracks continually develop in both grout layer and $\mathrm{PHC}$ pipe pile, and the curvature grows nonlinearly with the increasing of bending moment. Fourthly, phase CD: when the bending moment has increased to $979.7 \mathrm{kN} \cdot \mathrm{m}$, the yield starts to occur in the steel bars, and the curvatures sharply increase with small increasing of bending moment, which means the plastic hinge is formed.

As shown in Figure 5(b), when the bending moment is less than $272.5 \mathrm{kN} \cdot \mathrm{m}$, no crack initiates, and the flexural rigidity remains constant (phase OA). However, when the bending moment has increased to $272.5 \mathrm{kN} \cdot \mathrm{m}$, the cracks in the grout layer start to arise, and the flexural rigidity decreases sharply without bending moment increasing (phase $\mathrm{AA}_{1}$ ). After that, the flexural rigidity gradually decreases with the development of cracks in the grout layer (phase $\mathrm{A}_{1} \mathrm{~B}$ ). When the bending moment has increased to $536.9 \mathrm{kN} \cdot \mathrm{m}$, the cracks initiate in the $\mathrm{PHC}$ pipe pile, and the flexural rigidity decreases sharply again. However, the increasing lever arm of steel bars, due to the development of cracks and neutral axis shifting, makes the reduction rate of flexural rigidity to decrease with the moment increasing at phase BC. Finally, when the bending moment has exceeded $979.7 \mathrm{kN} \cdot \mathrm{m}$, the steel bars start to yield, and the rate of flexural rigidity reduction increases again at phase CD.

3.2. Proposed Method. The bending moment of the pile, caused by lateral loading at the pile head, varies with depth, and the initiation of cracks in the grout layer and the PHC pipe pile vary with depth also. Hence, the flexural rigidity varies along the length direction, and equation (1) is no longer suitable in this case.

When the flexural rigidity varies along the length direction, the following equation can be obtained from the force analysis of pure bending beam assumption:

$$
M(z)=E I \frac{\mathrm{d}^{2} y}{\mathrm{~d} z^{2}}
$$

where $M(z), E I$ and $y$ are the bending moment, flexural rigidity, and lateral displacement of the pile at the depth of $z$, respectively. Though this equation is derived by pure bending beam assumption, it is also suitable for the laterally loaded pile, providing the ratios of the length to diameter are greater than 5 because the effect of shear force on the pile deformation, in that condition, is tiny and negligible [21]. 


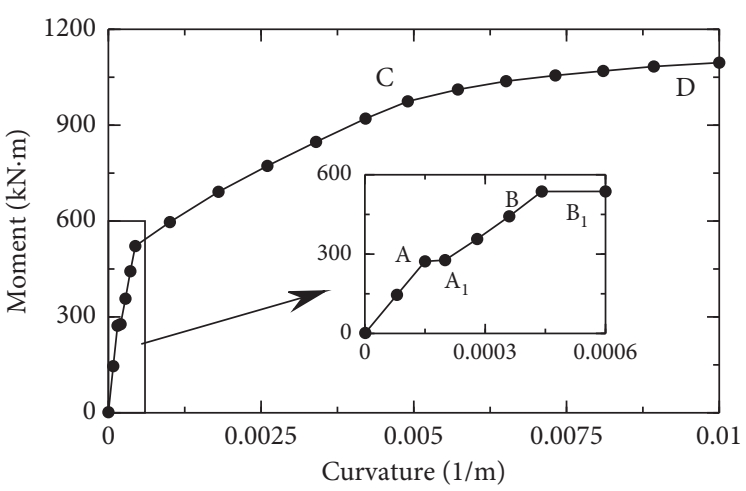

(a)

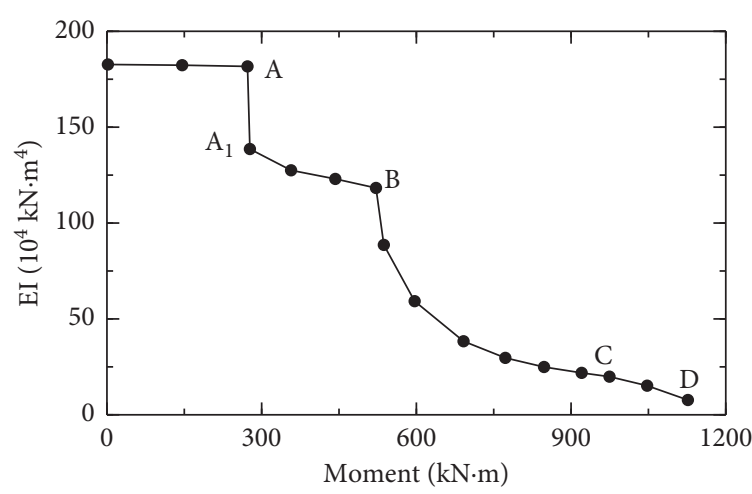

(b)

FIGURE 5: Effect of cracks on the bending behavior: (a) curvature-moment curves; (b) moment-EI curves.

TABle 2: Parameters used in the calculation of M-EI relationship of pile.

\begin{tabular}{lccc}
\hline \multirow{2}{*}{ Material } & \multicolumn{2}{c}{ Concrete } & \multirow{2}{*}{ Steel bar } \\
& PHC pipe pile & Grout layer & \\
\hline$f_{c}(\mathrm{MPa})$ & 73.6 & 36.0 & 1340 \\
$f_{t}(\mathrm{MPa})$ & 3.11 & 2.51 & 1340 \\
$E_{t}$ or $E(\mathrm{GPa})$ & 38.0 & 33.5 & 210 \\
$m$ & 1.5 & 2.0 & - \\
$\varepsilon_{0}$ & 0.00215 & 0.00200 & - \\
$\varepsilon_{c u}$ & 0.0030 & 0.0033 & - \\
\hline
\end{tabular}

Differentiating both sides of equation (10) twice with respect to $z$ and introducing the boundary conditions in, we obtain

$$
\frac{\mathrm{d}^{2} E I}{\mathrm{~d} z^{2}} \frac{\mathrm{d}^{2} y}{\mathrm{~d} z^{2}}+2 \frac{\mathrm{d} E I}{\mathrm{~d} z} \frac{\mathrm{d}^{3} y}{\mathrm{~d} z^{3}}+E I \frac{\mathrm{d}^{4} y}{\mathrm{~d} z^{4}}+p(y)=0,
$$

where $p(y)$ is the soil resistance function, which can be determined by $p-y$ curves. $E I$ is the flexural rigidity of the pile, which is related to the initiation and development of cracks. EI can be treated as a function of depth, under each given load condition. If we treat the function of EI as a constant, the first- and second-order differential of EI are both equal to zero, and equation (11) converts to equation (1).

Equation (11) is a fourth-order nonlinear differential equation and can be solved by the finite difference method or finite element method. However, the finite difference method would lead to unreasonable results when the flexural rigidity decreases sharply due to the initiation of cracks. In this article, the finite element method with one-dimension beam theory is employed to solve equation (11). The flexural rigidity of each beam element should be updated before each iteration according to the moment calculated by the previous iteration and the moment-flexural rigidity relationship.

Figure 6 shows the analysis process of the proposed method. Firstly, an appropriate $p-y$ curve is determined according to the soil profile, and the value of maximum load $H_{\max }$ and load increment $\mathrm{d} H$ are given. Secondly, solve equation (11) for the lateral displacement $y_{i}$, bending moment $M_{i}$, and soil resistance $P_{i}$. Thirdly, judge whether the results have satisfied the converge condition or not. If not, update the flexural rigidity of each beam element and solve equation (11) again. If satisfied, apply another load increment and repeat the above processes until the applied load has reached the maximum load.

3.3. Verification of the Proposed Method and Analysis of Cracking Effects on the Response of the Pile. The displacement at the ground surface and rotation of the pile top are calculated by the proposed method and the $p-y$ method, respectively. The cracking effect is counted in the proposed method but disregarded in the $p-y$ method. The calculated results of two methods are compared and plotted in Figure 7, as well as the field test results.

As depicted in Figure 7(a), the displacement calculated by the proposed method is much more close to the measured value, comparing with that computed by the $p-y$ method. When the lateral load is less than $150 \mathrm{kN}$, the displacement calculated by two methods is almost the same, and both are close to the measured displacement. When the lateral load exceeds $150 \mathrm{kN}$ and is less than $270 \mathrm{kN}$, the displacement calculated by the proposed method is slightly greater than the $p-y$ method. However, when the lateral load exceeded $270 \mathrm{kN}$, the displacement calculated by the proposed method is apparently greater than the $p-y$ method and much more close to the measured displacement. The conclusion can be drawn that the cracking effects would lead to a greater displacement at the ground, and the proposed method is able to accurately predict the displacement of the Drilled and Postgrouting Concrete Pipe Pile undergoing cracking.

The rotation of the pile top calculated by the proposed method is much more close to the measured value, comparing with the value by the $p-y$ method. As shown in Figure 7(b), when the lateral load is less than $150 \mathrm{kN}$, the rotation calculated by two methods is almost the same when the lateral load is less than $150 \mathrm{kN}$. However, when the load exceeds $150 \mathrm{kN}$, the rotation calculated by the proposed method is larger than that by the $p-y$ method, and the difference increases as the load increases. However, when the load has exceeded $270 \mathrm{kN}$, the rotation of the pile top calculated by the proposed method increases rapidly with load increasing and shows good consistency with measured value. 


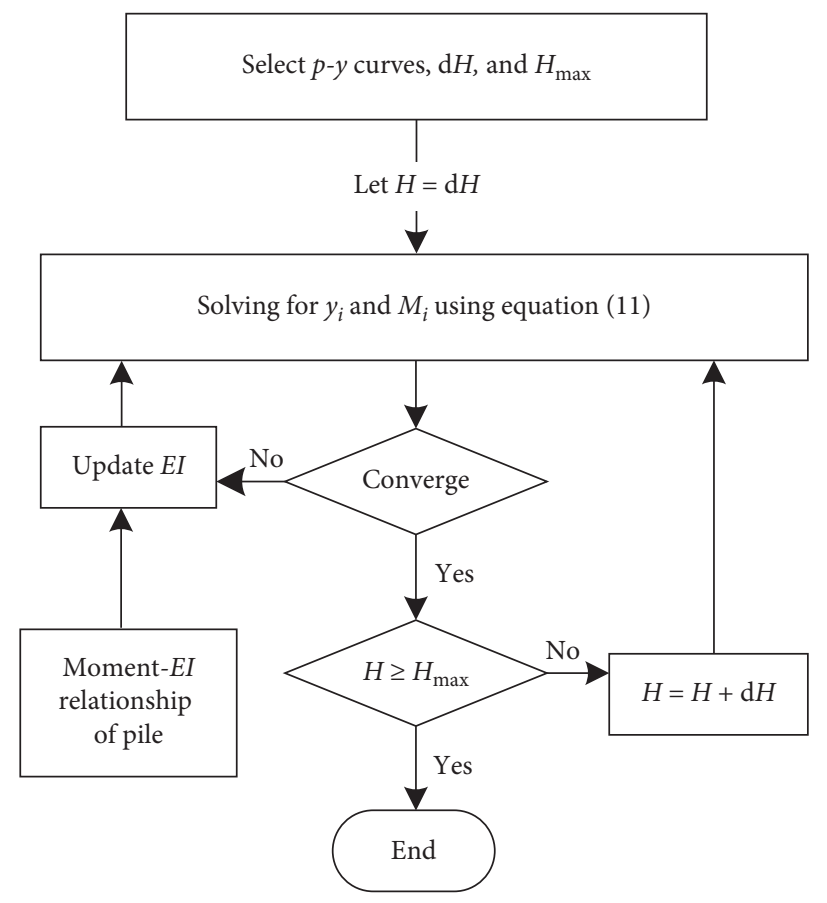

Figure 6: Analysis process of the proposed method.

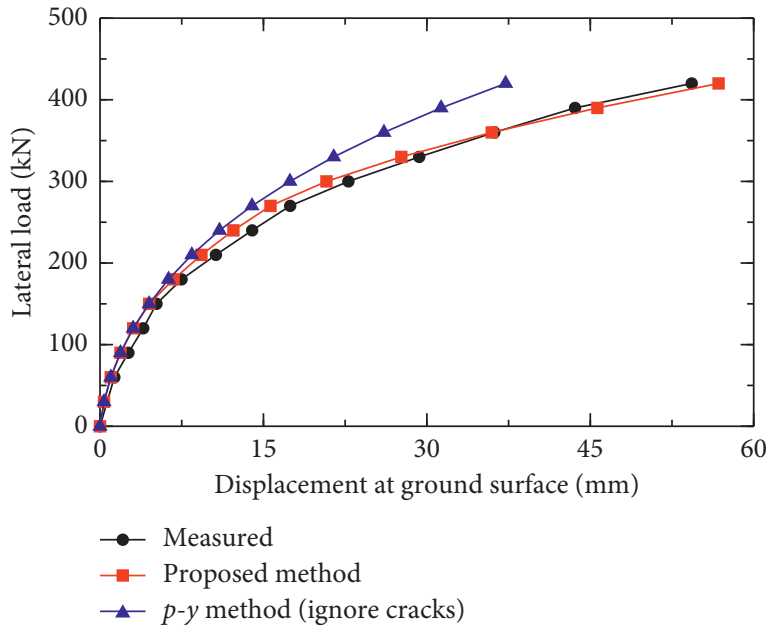

(a)

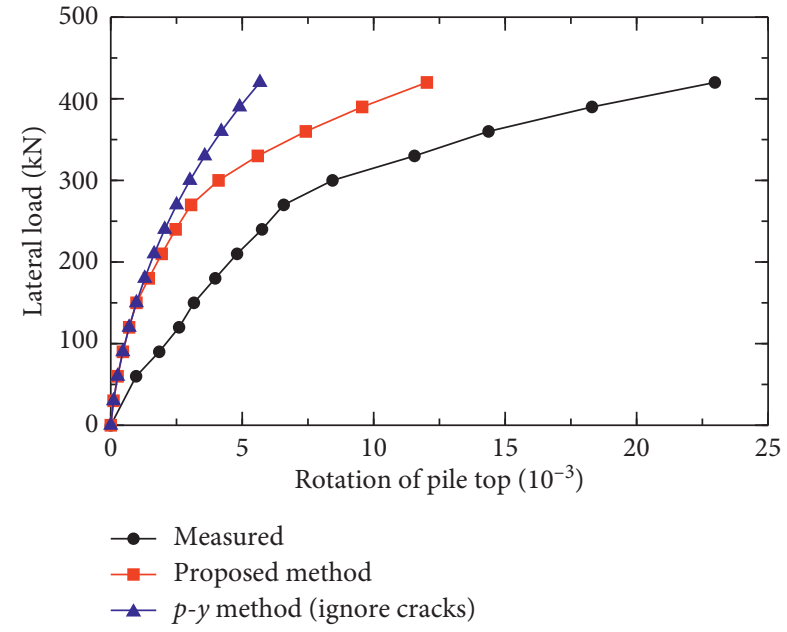

(b)

Figure 7: Comparison of calculated and measured results: (a) load-displacement curves; (b) load-rotation curves.

The cracking effects lead to a larger rotation at the pile top, and the proposed method can calculate the rotation of the pile top with preferable accuracy.

The maximum bending moment of the pile at different loads were computed by the proposed method, as well as the $p-y$ method, and the results are plotted in Figure 8. As shown in the load-maximum bending moment curve calculated by the proposed method, the lateral load corresponding to the bending moment of $272.5 \mathrm{kN} \cdot \mathrm{m}$ and $539.6 \mathrm{kN} \cdot \mathrm{m}$ is $156.6 \mathrm{kN}$ and $286.0 \mathrm{kN}$, respectively, which means the cracks start to initiate in grout and the PHC pipe pile when the lateral load is $156.6 \mathrm{kN}$ and $286.0 \mathrm{kN}$, respectively.
Before cracks initiated and the load is less than $156.6 \mathrm{kN}$, the maximum bending moment of two methods was exactly the same. The cracks in the grout layer have tiny influence on the maximum bending moment. When the load is equal to $270 \mathrm{kN}$ and cracks initiated in the grout layer only, for instance, the maximum bending moment computed by the proposed method, which is $509.6 \mathrm{kN} \cdot \mathrm{m}$, is just $3.8 \%$ smaller than the value computed by the $p-y$ method, which is $529.5 \mathrm{kN} \cdot \mathrm{m}$. However, the cracks in the PHC pipe pile have much more significant influence on the maximum bending moment. When the load is equal to $420 \mathrm{kN}$ and cracks initiated in the PHC pipe pile, for instance, the maximum 


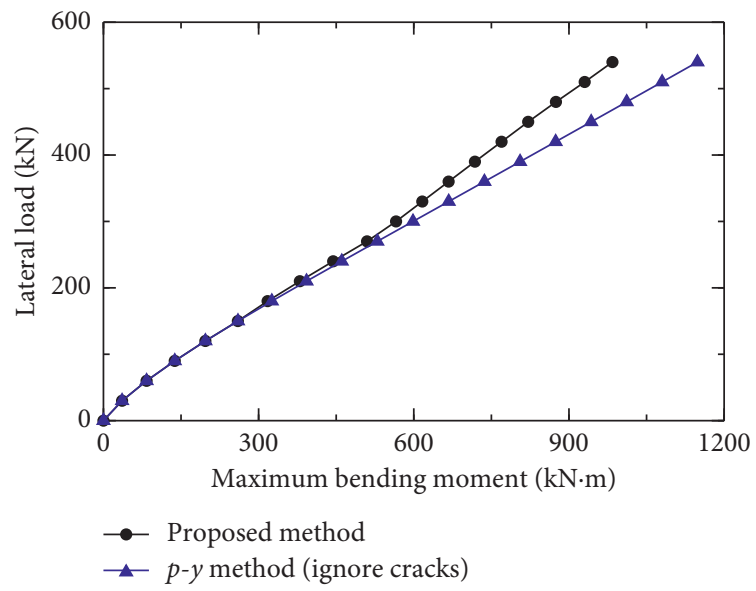

FIgURE 8: Load-maximum bending moment curves.

bending moment computed by the proposed method, which is $769.7 \mathrm{kN} \cdot \mathrm{m}$, is $12.0 \%$ smaller than by the traditional $p-y$ method, which is $874.3 \mathrm{kN} \cdot \mathrm{m}$.

The flexural rigidity of the pile at $150 \mathrm{kN}, 270 \mathrm{kN}$, and $420 \mathrm{kN}$ is plotted in Figure 9. When the load is $150 \mathrm{kN}$, the flexural rigidity remains constant along the depth, which means no cracks have initiated. When the load is $270 \mathrm{kN}$, however, the flexural rigidity of the pile at the depth of $1.25-8.20 \mathrm{~m}$ is lower than the initial flexural rigidity by $24.3 \%-34.7 \%$, which means the cracks have initiated in the grout layer at that depth range. When the load is $420 \mathrm{kN}$, the flexural rigidity of the pile at the depth of $0.73-1.68 \mathrm{~m}$ and $7.28-9.28 \mathrm{~m}$ is lower than the initial flexural rigidity by $24.3 \%-39.6 \%$, and the flexural rigidity of the pile at the depth of $1.68-7.28 \mathrm{~m}$ is lower than the initial flexural rigidity by $52.0 \%-83.6 \%$. It means that the cracks in the grout layer and the PHC pipe pile have initiated at the depth of $0.73-9.28 \mathrm{~m}$ and $1.68-7.28 \mathrm{~m}$, respectively, when the load is $420 \mathrm{kN}$.

The detail bending moment of the pile calculated by two methods is plotted in Figure 10. Before the cracks initiated and the load is $150 \mathrm{kN}$, there are no difference between the bending moment calculated by two methods. However, when the cracks have initiated in the grout layer only and the load is $270 \mathrm{kN}$, the bending moment calculated by the proposed method is slightly smaller than the $p-y$ method. After the cracks had initiated in both grout layer and PHC pipe pile and the load is $420 \mathrm{kN}$, the bending moment calculated by the proposed method was apparently smaller than the $p-y$ method. Moreover, the depth of maximum bending moment calculated by the proposed method was shallower than the $p-y$ method after the cracks had initiated. The cracking effects in the grout layer and the PHC pipe pile can not only reduce the bending moment but also shallow the depth of maximum bending moment.

The displacement of the pile at different depths calculated with and without counting cracking effects is plotted in Figure 11. Before cracks initiated in the grout layer or the PHC pipe pile and the load is $150 \mathrm{kN}$, there is no difference between the displacement calculated by two methods. When the load is $270 \mathrm{kN}$, the flexural rigidity reduction at the depth of $1.25-8.20 \mathrm{~m}$, due to the cracking effects in the grout layer, leads to greater pile curvature at that depth range, greater displacement at the ground surface, and smaller displacement at the pile tip. When the load is $420 \mathrm{kN}$, the cracks have initiated in both grout layer and PHC pipe pile, and the influence of cracking on the displacement is much greater. In a word, the cracking effects will lead to greater displacement at the ground surface and smaller displacement at the pile tip, and the influence of cracking in the PHC pipe pile is more significant than cracks in the grout layer.

\section{Conclusions}

A full-scale lateral load test on the Drilled and Postgrouted Concrete Pipe Pile was carried out to investigate its bearing characteristics. The law of flexural rigidity variety due to cracking effects was studied with the numerical method. A novel analysis method which can take the cracking effects into consideration was proposed. The validity of the proposed method was verified by the test results. Moreover, the cracking effects on the lateral response of the Drilled and Postgrouted Concrete Pipe Pile were discussed. Based on the test and analysis results, the following conclusions were reached:

(1) The cracks in the grout layer initiate at relatively low load level, which is $156.6 \mathrm{kN}$ in this case, and the cracks in the PHC pipe pile initiate at higher load level, which is $286.0 \mathrm{kN}$ in this case, due to the prestress. The depth range, where cracks initiated, expands as the load increases. When the lateral load increases up to $420 \mathrm{kN}$, the cracks initiate at the depth of $0.73-9.28 \mathrm{~m}$ and $1.68 \sim 7.28 \mathrm{~m}$ in the grout layer and the pipe pile, respectively.

(2) The flexural rigidity of the pile would reduce by $24.3 \%-83.6 \%$ due to the cracking effects. The displacement and rotation of the pile top would be significantly enlarged by the reduction of flexural rigidity. However, the bending moment of the pile would reduce slightly due to the cracking effect. It is necessary to update the flexural rigidity of the pile to improve the calculation accuracy of displacement 


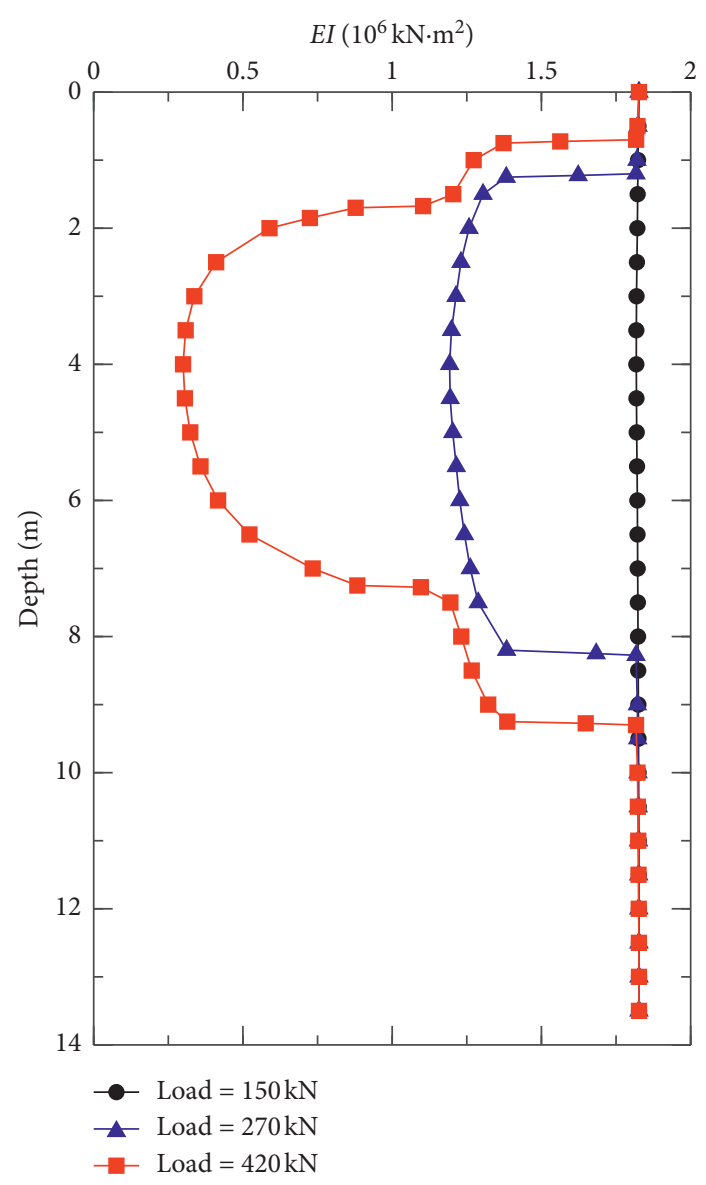

FIGURE 9: Flexural rigidity of the pile at different loads.

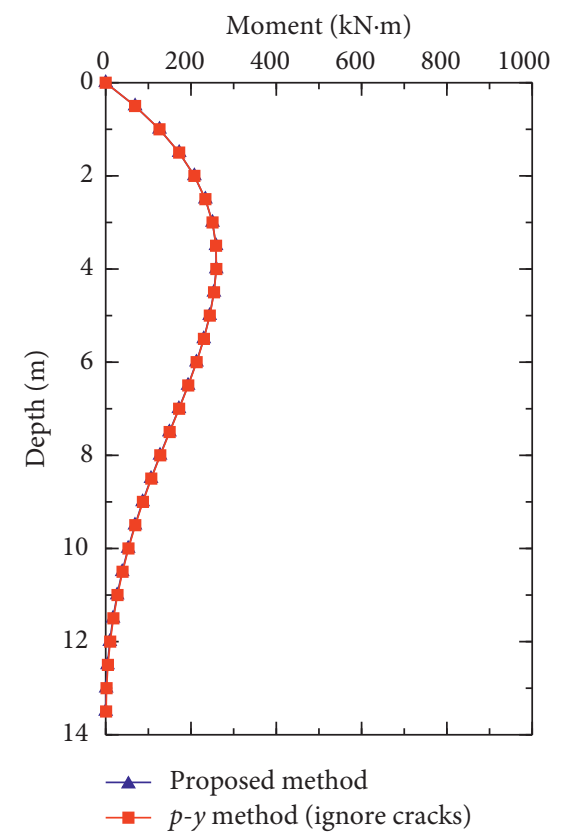

(a)

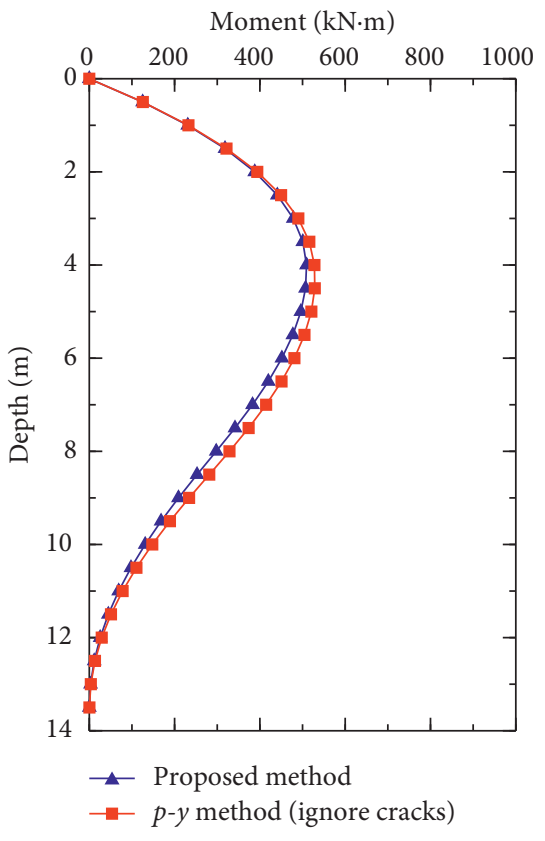

(b)

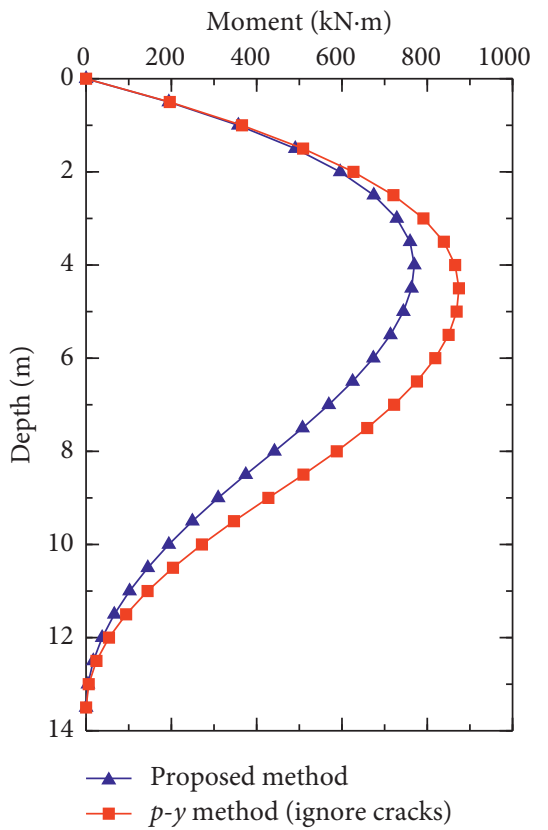

(c)

FIGURE 10: Influence of cracking on the bending moment: (a) load $=150 \mathrm{kN}$; (b) load=270 kN; (c) load $=420 \mathrm{kN}$. 


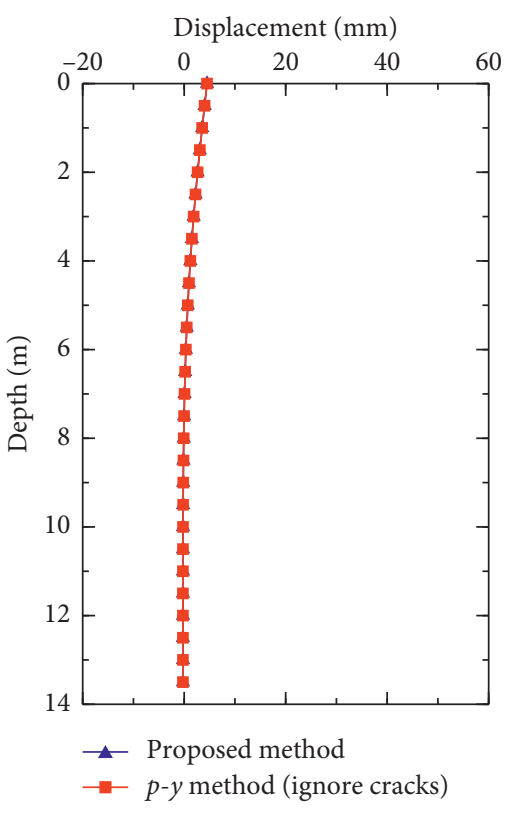

(a)

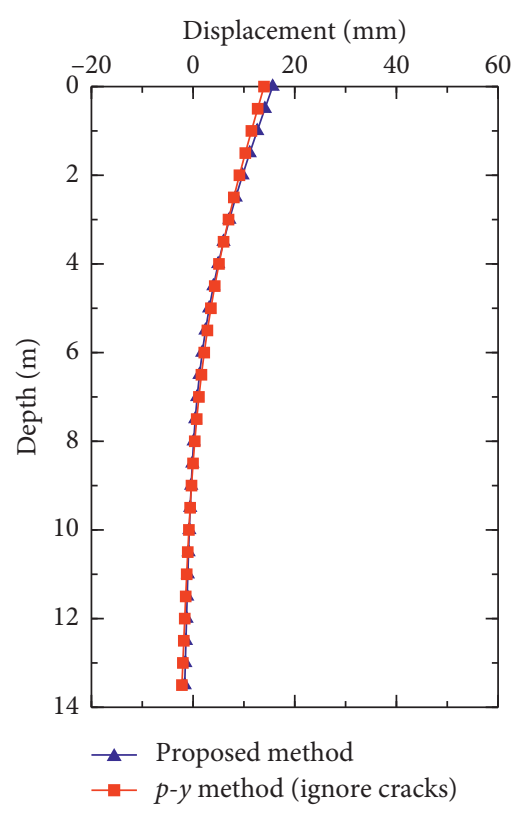

(b)

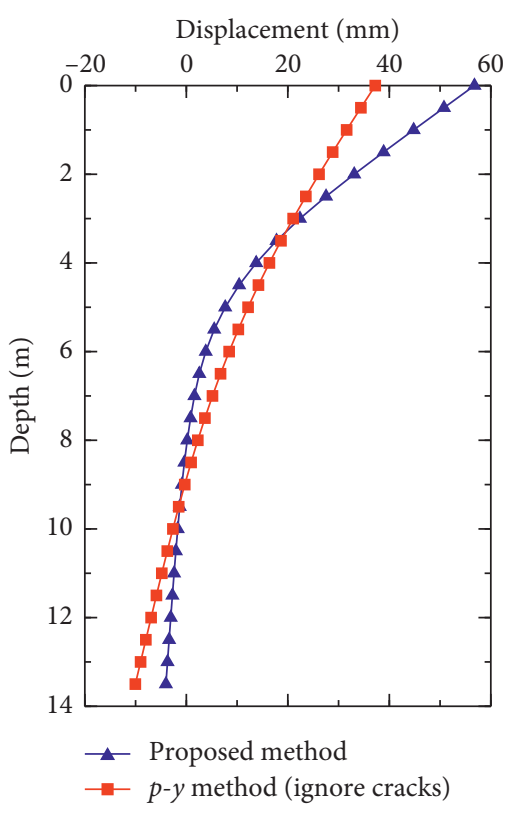

(c)

FIgURE 11: Influence of cracking on the pile displacement: (a) load $=150 \mathrm{kN}$; (b) load $=270 \mathrm{kN}$; (c) load $=420 \mathrm{kN}$.

and rotation of the pile top, as well as the bending moment of the pile.

(3) The method proposed in this article can accurately predict the responses of the Drilled and Postgrouting Concrete Pipe Pile undergoing cracking.

\section{Data Availability}

The figure data used to support the findings of this study are included within the supplementary information files; the table data used to support the findings of this study are included within the article.

\section{Disclosure}

Mr. Qing Fang is the senior engineer in charge of technical work of this project.

\section{Conflicts of Interest}

The authors declare that there are no conflicts of interest regarding the publication of this article.

\section{Acknowledgments}

This work was supported by the National Natural Science Foundation of China (Grant no. 51978540). The project was also supported by PowerChina Hubei Electric Engineering Co., Ltd.

\section{References}

[1] F. Shi and S. L. Hao, "Field test for horizontal bearing capacity of PHC pipe piles," Rock and Soil Mechanics, vol. 36, no. S2, pp. 617-622, 2015, in Chinese.
[2] X. C. Lu, G. W. Li, H. F. Pei, G. Y. Su, J. T. Wu, and A. C. Amenuvor, "Experimental investigations on load transfer of PHC piles in highway foundation using FBG sensing technology," International Journal of Geomechanics, vol. 17, no. 6, Article ID 04016123, 2017.

[3] L. C. Reese and H. Matlock, "Non-dimensional solutions for laterally loaded piles with soil modulus assumed proportional to depth," in Proceeding of 8th Texas Conference on Soil Mechanics and Foundation Engineering, pp. 1-41, Austin, TX, USA, 1956.

[4] C. F. Zhao, W. Z. Wang, C. Zhao, and Q. X. Liao, "Lateral bearing capacity of single piles under vertical and moment load sand," Chinese Journal of Rock Mechanics and Engineering, vol. 32, no. 1, pp. 184-190, 2013, in Chinese.

[5] H. G. Poulos, "Behavior of laterally loaded piles. I: single piles," Journal of the Soil Mechanics and Foundations Division, vol. 97, no. 5, pp. 711-731, 1971.

[6] H. G. Poulos, "Behavior of laterally loaded piles. II: pile groups," Journal of the Soil Mechanics and Foundations Division, vol. 97, no. 5, pp. 733-751, 1971.

[7] H. Matlock, "Correlations for laterally loaded piles in soft clay," in Proceedings of the 2nd Offshore Technology Conference, pp. 577-594, Houston, TX, USS, 1970.

[8] L. C. Reese, W. R. Cox, and F. D. Koop, "Field testing and analysis of laterally loaded piles in stiff clay," in Proceedings of the 7th Offshore Technology Conference, pp. 672-690, Houston, TX, USA, 1975.

[9] H. Lim and S. Jeong, "Simplified $p-y$ curves under dynamic loading in dry sand," Soil Dynamics and Earthquake Engineering, vol. 113, pp. 101-111, 2018.

[10] M. Ashour, G. Norris, and P. Pilling, "Lateral loading of a pile in layered soil using the strain wedge model," Journal of Geotechnical and Geoenvironmental Engineering, vol. 124, no. 4, pp. 303-315, 1998.

[11] L. Zhang, M. Zhao, and X. Zou, "Elastic-plastic solutions for laterally loaded piles in layered soils," Journal of Engineering Mechanics, vol. 139, no. 11, pp. 1653-1657, 2013. 
[12] M. F. Randolph, "The response of flexible piles to lateral loading," Géotechnique, vol. 31, no. 2, pp. 247-259, 1981.

[13] N. H. Levy, I. Einav, and M. F. Randolph, "Effect of recent load history on laterally loaded piles in normally consolidated clay," International Journal of Geomechanics, vol. 7, no. 4, pp. 277-286, 2007.

[14] W. C. Li, B. T. Zhu, and M. Yang, "Static response of monopile to lateral load in overconsolidated dense sand," Journal of Geotechnical and Geoenvironmental Engineering, vol. 143, no. 7, Article ID 04017026, 2017.

[15] Z. Yang, G. Li, W. Wang, and Y. Lv, "Study on the flexural performance of prestressed high strength concrete pile," KSCE Journal of Civil Engineering, vol. 22, no. 10, pp. 40734082, 2018.

[16] E. M. Comodromos, M. C. Papadopoulou, and I. K. Rentzeperis, "Effect of cracking on the response of pile test under horizontal loading," Journal of Geotechnical and Geoenvironmental Engineering, vol. 135, no. 9, pp. 1275-1284, 2009.

[17] L. C. Reese, "Analysis of laterally loaded piles in weak rock," Journal of Geotechnical and Geoenvironmental Engineering, vol. 123, no. 11, pp. 1010-1017, 1997.

[18] L.-Y. Xu, F. Cai, G.-X. Wang, G.-X. Chen, and Y.-Y. Li, "Nonlinear analysis of single reinforced concrete piles subjected to lateral loading," KSCE Journal of Civil Engineering, vol. 21, no. 7, pp. 2622-2633, 2017.

[19] G. S. Li, Y. J. Pan, and X. H. Meng, "Comparative experimental analysis of physical and mechanical properties of saturated soft soil under different sampling methods," Journal of Engineering Geology, vol. 27, no. 3, pp. 550-558, 2019.

[20] Ministry of Housing and Urban-Rural Development of the People's Republic of China, Code for Structural Design of Concrete (GB50010-2010), China Architecture \& Building Press, Beijing, China, 2015.

[21] X. Deng and Y. J. Xu, Mechanics of Materials, Wuhan University Press, Wuhan, China, 1st edition, 2002. 